(C) Bastian D., Martiana I.K., 2020

DOI 10.18019/1028-4427-2020-26-2-212-215

\title{
Comparison between strontium administration and ibandronate injection effects on bone density of post-ovariectomy Wistar rat
}

\author{
D. Bastian, I.K. Martiana \\ Department of Orthopedic and Traumatology, Dr. Soetomo Teaching Hospital, Faculty of Medicine, Universitas Airlangga, Surabaya 60285, \\ Indonesia
}

\begin{abstract}
Introduction Osteoporosis is a disease causing high morbidity with increasing prevalence. It is one of chronic diseases caused by reduced bone mass that subsequently decreases bone strength and increases fracture risks. Pharmacologic treatments for osteoporosis include antiresorptive agent (bisphosphonate) and bone-forming agent (strontium ranelate), so further research is needed to compare these two medications. Objectives We aimed to histopathologically compare bone density in post-menopause white rats after being treated with strontium and ibandronate. Material and methods 45 ovariectomized female rats were divided into three groups. The subjects in the first group were only ovariectomized (control). The strontium group was given daily oral strontium at a dose of $625 \mathrm{mg} / \mathrm{kg}$ BW/day for 60 days. The ibandronate group was given one subcutaneous ibandronate injection at a dose of $1 \mu \mathrm{g} / \mathrm{kg}$ BW/day for 60 days. We measured osteoclasts, osteoblasts, trabecula area and cortical thickness. Results The animals in ibandronate and strontium groups showed a significant increase (p < 0.005) in osteoblasts and significant decrease in osteoclasts compared to the control group. The subjects in both groups had a significantly thicker cortex and a larger trabecula area than in the control group. The subjects in the strontium group had more osteoblasts and thicker cortex than in the ibandronate group. Conclusion Strontium had a double effect, increasing osteoblasts and inhibiting osteoclasts. On the other hand, ibandronate had only a strong antiresorptive effect, but a lower osteoblast effect. It could be inferred that strontium was more effective in increasing bone density as compared to ibandronate. Keywords: ibandronate, osteoblast, osteoclast, osteoporosis, strontium, trabecula
\end{abstract}

\section{INTRODUCTION}

Osteoporosis is a disease characterized by decreasing bone mass, followed by impaired bone microarchitecture that subsequently results in bone fragility and bone fracture. Patient's bone density in osteoporosis is lower than 2.5 standard deviations from the peak bone mass [1]. Around 25 million persons in the European Union, America and Japan suffer from this disease, with one in three postmenopausal women and one in five men aged over 50.

Osteoporosis is the most common bone disorder in the European and American countries. The National Osteoporosis Foundation reported that 44 million Americans had osteoporosis risks due to low bone density [2]. Ten million were diagnosed with this disease, and $\$ 47$ million were spent daily for more than 1.5 million cases fractures per year. The International Osteoporosis Foundation (IOF) reported that 3.79 million Europeans suffered from osteoporosis-related bone fractures, which 890,000 were hip fractures [3]. The IOF 2013 report stated that osteoporosis developed in 173/100,000 Indonesians per year; osteoporosisrelated vertebral fractures occurred in $35 \%$ of males and $20.6 \%$ of females aged over 65 [4]. The number of subjects with diagnosed osteoporosis may double in the next 50 years due to an increasing number of elderly population and lifestyle factors [5].

This osteoporosis phenomenon raises huge concerns since it results in increased morbidity and mortality. Therefore, preventive (e.g. physical activity) and therapeutic (e.g. medication) efforts are necessary to increase bone mass quality. Various medications and treatments for prevention of osteoporosis are currently available, yet no study compares such medications head-to-head [6].

Popular osteoporosis preventive and treatment drugs are bisphosphonate and strontium. Ibandronate, a potent N-containing bisphosphonate, inhibits osteoclast activity and prevents bone resorption. Ibandronate is considered to be effective but bisphosphonates only suppress osteoclasts and do not have effect on osteoblasts. Therefore, there is instability in bone turnover process. Some atypical subtrochanteric and femur shaft fractures occur in patients with long-term bisphosphonate administration [7]. Strontium ranelate is a new antiosteoporosis agent with two working mechanisms: mild anabolic and antiresorptive effects in bone tissue [8].

The more drug regimens varied in osteoporosis management, the more varied the drug selections used through different activities and work point. Nevertheless, the efficacy of anti-osteoporosis agents has not been discovered yet; particularly, the superiority of strontium ranelate over ibandronate. Therefore, we were interested in comparing strontium and ibandronate therapy effectiveness in experimental animals. 


\section{METHODS}

This is an experimental laboratory study using randomized post-test only control group design [9]. The research was carried out for 90 days from the first day after ovariectomy at the Institute of Tropical Disease, Universitas Airlangga, Surabaya, Indonesia.

Samples in each group were taken randomly. The inclusion criteria were female Wistar rats aged 2-3 months, weighing $200 \mathrm{~g}$, unpregnant and healthy. Research instruments included cage sized $30 \times 40 \times 15 \mathrm{~cm}$, syringe, NGT no. 10, scissor, surgical suture, anesthesia jar and a microscope set to evaluate bone histology.

Treatment materials were subcutaneous ibandronate injection at a dose of $1 \mu \mathrm{g} / \mathrm{kg} \mathrm{BW} /$ day for 60 days at the beginning of treatment in Group I, with a total dose of $60 \mu \mathrm{g} / \mathrm{kg}$ BW/day. On the other hand, Group II had oral strontium ranelate administration at a dose of $625 \mathrm{mg} / \mathrm{kg}$ BW/day. Test materials included intramuscular injection of ketamine solution at a dose of $5 \mathrm{mg} / \mathrm{kg}$ (anesthesia occurred after 10 minutes and was maintained for 2540 minutes), chloroform for anesthesia at the end of treatment, formalin, gauze and labeling paper.

Research procedures were divided into 5: acclimatization, experimental animal grouping, treatment, anesthesia and bone density measurement. Acclimatization of the experimental animals was carried out for seven days under laboratory conditions with standard ad libitum feeding and drinking procedures. Experimental animal grouping was random grouping of subjects into three groups. Subjects in the control group were only ovariectomized. Subjects in Group I were treated with ovariectomy and ibandronate. On the other hand, subjects in Group II were treated with ovariectomy and strontium ranelate. Subjects in the control group was treated with ovariectomy, followed by caring and treatment for 60 days after 30 days. Subjects in the Group I were treated with ovariectomy, followed by a subcutaneous ibandronate injection after 30 days. On the other hand, subjects in the Group II were treated with daily oral strontium administration for 60 days using NTG no. 10 that directly entered into the stomach.

Ovariectomy was conducted by taking both ovaries and ligations of both oviducts through an incision in the animal's abdomen. Osteoporosis condition was theoretically obtained within a month. The first anesthesia was performed after acclimatization using intramuscular ketamine solution at a dose of $10 \mathrm{mg} / \mathrm{kg}$ BW approximately for 10 minutes. The last anesthesia was conducted by inserting chloroform-induced cotton and the rats into anesthesia jar approximately for 3 minutes. Bone density was measured in the rats' proximal tibia and was evaluated by measuring osteoblasts, osteoclasts, trabecula area and cortical thickness using a microscope.

Statistics analysis included descriptive statistic test, normality test and ANOVA test. The data were processed using SPSS 12 (SPSS, Inc., Chicago, IL.).

\section{RESULTS}

The data included independent and dependent variables obtained through measurement. The data were analyzed using descriptive statistics to obtain distribution of measurement results and to determine proper statistical calculation. We obtained osteoblasts and osteoclasts (cell/15625 $\mu^{2}$ ), trabecula area $\left(\mu^{2}\right)$ and cortical thickness $(\mu)$ which were described and tested using significance level of $5 \%$ and were processed using SPSS 12.

We examined subjects in the control group (ovariectomy without treatment), Group I (ovariectomy with a subcutaneous ibandronate injection at a dose of $1 \mu \mathrm{g} / \mathrm{kg}$ BW/day) and Group II (ovariectomy with a 60-day oral strontium administration at a dose of $625 \mathrm{mg} / \mathrm{kg}$ BW/day). Highest osteoblast numbers were found in the Group II (10.36 cells/15625 $\mu^{2}$; Table 1). Group I had the lowest number of osteoclasts $\left(0.51\right.$ cells $\left./ 15625 \mu^{2}\right)$. Group II had more osteoclasts than Group I, but their number was smaller than in the control group. Group I and II had a slight difference in the measurements of trabecula area
(5302.33 $\mu^{2}$ vs $5488.33 \mu^{2}$ ). The highest cortical thickness was found in Group II (305.78 $\mu$ ).

We employed Kolmogorov-Smirnov test to evaluate data normality. The test found the data were normally distributed ( $p>0.05$; Table 2$)$. The variance test aimed to find treatment effects among the groups on the dependent variables (osteoblasts, osteoclasts, trabecula area and cortical thickness).

ANOVA test found a significant difference between the treatment groups and the control group $(\mathrm{p}<0.05)$ (Table 3). We further conducted post hoc test to find which group provided most different results (Table 4). The test showed a significant difference of all variables between the control group and the treatment groups, both ibandronate and strontium $(p<0.05)$. There were significant differences of osteoblasts and cortical thickness between Group I and Group II ( $p<0.05)$. Nevertheless, both groups had no significant difference in terms of osteoclasts and trabecula area $(p>0.05)$.

Table 1

Variable mean and SD

\begin{tabular}{|l|c|c|c|c|c|c|c|c|}
\hline \multirow{2}{*}{ Groups } & \multicolumn{2}{|c|}{ Osteoblasts $\left(\mathrm{cell} / 15625 \mu^{2}\right)$} & \multicolumn{2}{c|}{ Osteoclasts $\left(\mathrm{cell} / 15625 \mu^{2}\right)$} & \multicolumn{2}{c|}{ Trabecula area $\left(\mu^{2}\right)$} & \multicolumn{3}{c|}{ Cortical thickness $(\mu)$} \\
\cline { 2 - 9 } & Mean & SD & Mean & SD & Mean & SD & Mean & SD \\
\hline Control & 4.33 & 0.80 & 1.08 & 0.29 & 2447.92 & 582.55 & 136.17 & 35.88 \\
\hline Ibandronate & 8.48 & 1.55 & 0.51 & 0.28 & 5302.23 & 804.60 & 244.92 & 43.84 \\
\hline Strontium & 10.36 & 1.15 & 0.71 & 0.30 & 5488.33 & 1380.21 & 305.78 & 37.13 \\
\hline
\end{tabular}


Data normality test

\begin{tabular}{|c|c|c|c|c|}
\hline Groups & $\mathrm{p}$ Osteoblasts & $\mathrm{p}$ Osteoclasts & $\mathrm{p}$ Trabecula area & $\mathrm{p}$ Cortical thickness \\
\hline Control & 0.937 & 0.084 & 0.980 & 0.984 \\
\hline Ibandronate & 0.685 & 0.094 & 0.951 & 0.672 \\
\hline Strontium & 0.994 & 0.868 & 0.437 & 0.988 \\
\hline
\end{tabular}

Table 3

ANOVA test for osteoblasts, osteoclasts, trabecula area and cortical thickness

\begin{tabular}{|l|c|c|}
\hline \multicolumn{1}{|c|}{ Variables } & F & P \\
\hline Osteoblasts & 68.66 & 0.00 \\
\hline Osteoclasts & 12.66 & 0.00 \\
\hline Trabecula area & 38.76 & 0.00 \\
\hline Cortical thickness & 50.88 & 0.00 \\
\hline
\end{tabular}

Table 4

Differentiation test between variables

\begin{tabular}{|l|l|c|c|c|c|}
\hline \multirow{2}{*}{\multicolumn{2}{|c|}{ Groups }} & \multicolumn{4}{c|}{ P } \\
\cline { 3 - 6 } \multicolumn{2}{|c|}{ Control } & Osteoblasts & Osteoclasts & Trabecula area & Cortical thickness \\
\hline \multirow{3}{*}{ Ibandronate } & Ibandronate & 0.000 & 0.000 & 0.000 & 0.000 \\
\cline { 2 - 6 } & Strontium & 0.000 & 0.006 & 0.000 & 0.000 \\
\hline \multirow{2}{*}{ Strontium } & Control & 0.000 & 0.000 & 0.000 & 0.000 \\
\cline { 2 - 6 } & Strontium & 0.001 & 0.114 & 0.647 & 0.001 \\
\cline { 2 - 6 } & Control & 0.000 & 0.006 & 0.000 & 0.000 \\
\cline { 2 - 6 } & Ibandronate & 0.001 & 0.114 & 0.647 & 0.001 \\
\hline
\end{tabular}

\section{DISCUSSION}

In this study, the highest morbidity was found in the group with oral strontium administration (40\%). It might be caused due to high stress levels as a result of daily oral admission. We evaluated osteoblasts and osteoclasts in two different treatments since these two cells have important roles in bone remodeling (turnover). Histological study of these cells is relatively easy since it only requires simpler and more affordable hematoxylin and eosin staining compared to other techniques using immunohistochemistry. Bone density could also be measured by determining trabecula area and cortical thickness [10].

The average number of osteoclasts in the ibandronate group was 0.51 cells $/ 15625 \mu^{2}$, significantly lower than in the control group (1.08 cells/15625 $\mu^{2}$ ). The number of osteoclasts in the group was also lower than in the strontium group, but it was no significantly different $(p>0.005)$. It could be inferred that both ibandronate and strontium are equally effective in decreasing osteoclasts since ibandronate has strong antiresorptive effects by inhibiting osteoclast differentiation and increasing osteoclast apoptosis [11]. In addition, strontium has a mild antiresorptive effect [12].

Strontium administration increased the number of osteoblasts $\left(10.36\right.$ cells/ $\left.15625 \mu^{2}\right)$; it was significantly higher than in the control group (4.33 cells $/ 15625 \mu^{2}$ ). The subjects in the ibandronate group also showed a significant increase in osteoblasts (8.48 cells $/ 15625 \mu^{2}$ ) compared to the control group. The number of osteoblasts in the strontium group was significantly higher than in the ibandronate group. It could be inferred that strontium is better than ibandronate in increasing osteoblasts [13].

Strontium has a double effect on the bone turnover process by enhancing bone formation through increasing osteoblast differentiation of its progenitor cells, prolonging osteoblast life span and having mild antiresorptive effect. This double effect results in bone turnover process stability.

Most literature sources agree that bisphosphonate has no direct effect on osteoblasts. Nevertheless, von Knoch et al. in their study found that bisphosphonate could increase osteoblast differentiation and inhibit osteoblast apoptosis through a mechanism that has not been fully understood yet [14]. Only nitrogencontaining bisphosphonate treatment, such as ibandronate and zoledronate, had these effects [15].

We used trabecula area and cortical thickness parameters in measuring bone density. Increased trabecula area was found in ibandronate and strontium groups with average value of 5,302.23 $\mu^{2}$ and $5,488.33 \mu^{2}$, respectively. This increment was significantly higher than in the control group $\left(2,447.92 \mu^{2}\right)$. The strontium group had a larger trabecula area than the ibandronate group, but it was not significantly different $(\mathrm{p}>0.05)$. Increased cortical thickness was found in both groups $\left(244,92 \mu^{2}\right.$ vs $\left.305,78 \mu^{2}\right)$, significantly higher than the control group $\left(136,17 \mu^{2}\right)$. There was a significant difference in cortical thickness between strontium and ibandronate 
groups. Strontium is superior to ibandronate in increasing bone density. It can increase bone turnover stability as it increases osteoblast activity and exhibits a mild suppression on osteoclasts, causing bones to become denser which is characterized by a wider trabecula area and a thicker cortex.

Ibandronate as a strong antiresorptive drug has a direct effect on inhibiting and differentiating osteoclasts that subsequently decreases bone resorption process. It should be noted that bone turnover is a coupling mechanism, in which bone resorption will be automatically followed by bone formation or deposition process by osteoblasts. It could be inferred that ibandronate inhibits the bone turnover process. Short-term bisphosphonate usage still reluts in normal bone microarchitecture quality; nevertheless in longterm usage ( $>5$ years), bisphosphonate may cause atypical fracture in long bones [16].

\section{CONCLUSION}

Strontium and ibandronate have been found to increase the number of osteoblasts, trabecula area and cortical thickness, and to decrease the number

of osteoclasts. Strontium is more effective than ibandronate in osteoporosis treatment since it increases the number of osteoblasts and cortical thickness.

\section{REFERENCES}

1. D.R. Biphosphonate Treatment on Osteoporosis. Syposium Update on Osteoporosis. 2000. Surabaya, pp 57-77.

2. National Osteoporosis Foundation. National Osteoporosis Foundation: Physician's Guide to Prevention and Treatment of Osteoporosis. 1999. Washington DC.

3. Reginster J.Y. Antifracture Efficacy of Currently Available Therapies for Postmenopausal Osteoporosis. Drugs, 2011, vol. 71, no. 1, pp. 65-78. DOI: 10.2165/11587570-000000000-00000.

4. Kwok A.W.L., Leung J.C.S., Chan A.Y.H., Au B.S.K., Lau E.M.C., Yurianto H., Yuktanandana P., Yoshimura N., Muraki S., Oka H., Akune T., Leung P.C. Prevalence of vertebral fracture in Asian men and women: Comparison between Hong Kong, Thailand, Indonesia and Japan. Public Health, 2012, vol. 126, no. 6, pp. 523-531. DOI: 10.1016/j.puhe.2012.03.002.

5. Badan Pusat Statistik. Proyeksi Penduduk Indonesia 2010-2035. 2013. Jakarta. BPS-Statistics Indonesia. (In Indonesia)

6. Vestergaard P. New strategies for osteoporosis patients previously managed with strontium ranelate. Therapeutic Advances in Musculoskeletal Disease, 2014, vol. 6, no. 6, pp. 217-225. DOI: 10.1177/1759720X14552070.

7. Daroszewska A. Prevention and treatment of osteoporosis in women: an update. Obstetrics Gynaecology and Reproductive Medicine, 2015, vol. 25, no. 7, pp. 181-187. DOI: 10.1016/j.ogrm.2015.04.001.

8. Canalis E. The divalent strontium salt S12911 enhances bone cell replication and bone formation in vitro. Bone, 1996, vol. 18, no. 6, pp. 517-523. DOI: 10.1016/8756-3282(96)00080-4

9. Zainuddin M. Metodologi Penelitian. 2000. Surabaya. Universitas Airlangga. (In Indonesia)

10.Bauss F., Lalla S., Endele R., Hothorn L.A. Effects of treatment with ibandronate on bone mass, architecture, biomechanical properties, and bone concentration of ibandronate in ovariectomized aged rats. J. Rheumatol., 2002, vol. 29, no. 10, pp. $2200-2208$.

11. Bauss F., Schimmer R.C. Ibandronate: the first once-monthly oral bisphosphonate for treatment of postmenopausal osteoporosis. Ther Clin Risk Manag, 2006, vol. 2, no. 1, pp. 3-18.

12.Ammann P., Shen V., Robin B., Mauras Y., Bonjour J.P., Rizzoli R. Strontium Ranelate Improves Bone Resistance by Increasing Bone Mass and Improving Architecture in Intact Female Rats. J. Bone Miner Res., 2004, vol. 19, no. 12, pp. 2012-2020. DOI: 10.1359/jbmr.040906.

13.Bain S.D., Jerome C., Shen V., Dupin-Roger I., Ammann P. Strontium ranelate improves bone strength in ovariectomized rat by positively influencing bone resistance determinants. Osteoporos Int., 2009, vol. 20, no. 8, pp. 1417-1428. DOI: 10.1007/s00198008-0815-8.

14.Knoch F.V., Jaquiery C., Kowalsky M., Schaeren S., Alabre C., Martin I., Rubash H.E., Shanbhag A.S. Effects of bisphosphonates on proliferation and osteoblast differentiation of human bone marrow stromal cells. Biomaterials, 2005, vol. 26, no. 34, pp. 69416949. DOI: 10.1016/j.biomaterials.2005.04.059

15.Koch F.P., Yekta S.S., Merkel C., Ziebart T., Smeets R. The impact of bisphosphonates on the osteoblast proliferation and Collagen gene expression in vitro. Head Face Med., 2010, vol. 6, no. 1, pp. 12. DOI: 10.1186/1746-160X-6-12

16.Kharwadkar N., Mayne B., Lawrence J.E., Khanduja V. Bisphosphonates and atypical subtrochanteric fractures of the femur. Bone Joint Res., 2017, vol. 6, no. 3, pp. 144-153. DOI: 10.1302/2046-3758.63.BJR-2016-0125.R1.

Received: 21.01.2020

Information about the authors:

1.Donny Bastian, Dr, SpOT,

Dr. Soetomo Teaching Hospital, Universitas Airlangga, Surabaya, Indonesia,

Email: donnybastianfkunair@gmail.com

2.I Ketut Martiana, Dr, SpOT(K),

Dr. Soetomo Teaching Hospital, Universitas Airlangga, Surabaya, Indonesia,

Email: iketutmartiana@gmail.com 